\title{
A fast selenium derivatization strategy for crystallization and phasing of RNA structures
}

\author{
VINCENT OLIERIC, ${ }^{1,5}$ ULRIKE RIEDER, ${ }^{2,5}$ KATHRIN LANG, ${ }^{2}$ ALEXANDER SERGANOV, ${ }^{3}$ \\ CLEMENS SCHULZE-BRIESE, ${ }^{1}$ RONALD MICURA, ${ }^{2}$ PHILIPPE DUMAS, ${ }^{4,6}$ and ERIC ENNIFAR ${ }^{4,6}$ \\ ${ }^{1}$ Swiss Light Source, Paul Scherrer Institute, CH-5232 Villigen, Switzerland \\ ${ }^{2}$ Institute of Organic Chemistry, Center for Molecular Biosciences, Leopold Franzens University, A-6020 Innsbruck, Austria \\ ${ }^{3}$ Structural Biology Program, Memorial Sloan-Kettering Cancer Center, New York, New York 10021, USA \\ ${ }^{4}$ Architecture et Réactivité de I'ARN, Institut de Biologie Moléculaire et Cellulaire, Université Louis Pasteur/CNRS UPR 9002, F-67084 \\ Strasbourg, France
}

\begin{abstract}
Site-specific 2 '-methylseleno RNA labeling is a promising tool for tackling the phase problem in RNA crystallography. We have developed an efficient strategy for crystallization and structure determination of RNA and RNA/protein complexes based on preliminary crystallization screening of $2^{\prime}-\mathrm{OCH}_{3}$-modified $\mathrm{RNA}$ sequences, prior to the replacement of $2^{\prime}-\mathrm{OCH}_{3}$ groups with their $2^{\prime}-\mathrm{SeCH}_{3}$ counterparts. The method exploits the similar crystallization properties of $2^{\prime}-\mathrm{OCH}_{3}-$ and $2^{\prime}-\mathrm{SeCH}_{3}$-modified RNAs and has been successfully validated for two test cases. In addition, our data show that $\mathbf{2}^{\prime}$-SeCH - $^{- \text {modified }}$ RNA have an increased resistance to X-ray radiolysis in comparison with commonly used 5-halogen-modified RNA, which permits collection of experimental electron density maps of remarkable quality.
\end{abstract}

Keywords: X-ray crystallography; RNA structure; selenium; structure determination

\section{INTRODUCTION}

The growing number of biologically important RNA sequences demands a fast and reliable method for crystallization and de novo three-dimensional structure determination of RNA. 2'-methylseleno $\left(2^{\prime}-\mathrm{SeCH}_{3}\right)$ labeling of nucleic acids has been developed as an alternative to two broadly used phasing techniques, to the halogenation of pyrimidines and to soaking crystals in heavy atom salt solutions ( Du et al. 2002; Teplova et al. 2002; Carrasco et al. 2004; Jiang et al. 2007; Pallan and Egli 2007). The 2 '- $\mathrm{SeCH}_{3}$-labeling method, suited for the determination of RNA structures, relies on the crystallization of RNA molecules that have natural nucleoside(s) substituted for

\footnotetext{
${ }^{5}$ These authors contributed equally to this work.

${ }^{6}$ Present address: Architecture et Réactivité de l'ARN, Université de Strasbourg, CNRS, IBMC, 15 rue René Descartes, F-67084 Strasbourg, France.

Reprint requests to: Eric Ennifar, Architecture et Réactivité de l'ARN, Institut de Biologie Moléculaire et Cellulaire, Université Louis Pasteur/CNRS UPR 9002, 15 Rue René Descartes, F-67084 Strasbourg, France; e-mail: e.ennifar@ibmc.u-strasbg.fr; fax: 33-3-88602218. Article published online ahead of print. Article and publication date are at http://www.rnajournal.org/cgi/doi/10.1261/rna.1499309.
}

their $2^{\prime}-\mathrm{SeCH}_{3}$-modified counterparts during chemical RNA synthesis. The $2^{\prime}-\mathrm{SeCH}_{3}$ labeling allows use of the powerful multiwavelength anomalous dispersion (MAD) technique for structure determination and, in contrast to the halogenation of pyrimidines, can be utilized for the modification of all four standard nucleosides (adenosine, guanosine, uridine, and cytidine) (Hobartner and Micura 2004; Hobartner et al. 2005; Moroder et al. 2006; Puffer et al. 2008). Moreover, the combination of the $2^{\prime}-\mathrm{SeCH}_{3}$ labeling with enzymatic ligation expands the $\sim 40$ nucleotide (nt) limit of chemically synthesized Se-labeled RNA to large biologically relevant RNA molecules (Hobartner et al. 2005). The Se-labeling strategy was successfully applied to determine several nucleic acid structures, including the structure of a 49-nt Diels-Alder ribozyme determined by single-wavelength anomalous dispersion (SAD) (Hobartner et al. 2005; Serganov et al. 2005).

Due to the high costs of preparative Se-labeled RNA synthesis, initial crystallization trials have to be performed using unmodified RNA. However, the substitution of the 2 '-OH group for the $2^{\prime}-\mathrm{SeCH}_{3}$ group can alter crystal contacts, thereby resulting in the deterioration of crystal quality and in interference with crystallization conditions established for unmodified RNA (Hobartner et al. 2005; 


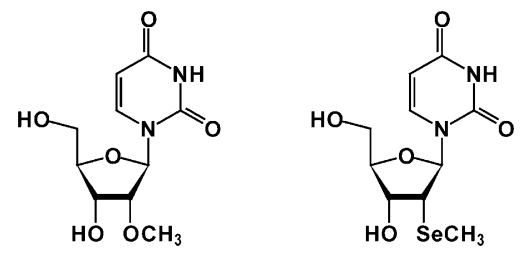

FIGURE 1. Chemical structure of $2^{\prime}$-methylseleno-uridine and $2^{\prime}$-Omethyl-uridine.

Moroder et al. 2006). As a consequence, crystallization conditions either cannot be reproduced or require the synthesis of several RNA sequences with $2^{\prime}-\mathrm{SeCH}_{3}$ modifications at various positions (Hobartner et al. 2005; Moroder et al. 2006). To obtain a reproducible transition from the nonmodified RNA to the Se-labeled RNA, we propose a new crystallization strategy based on a broad preliminary crystallization screening of the RNA sequences with 2 '-OH group(s) substituted for $2^{\prime}-\mathrm{OCH}_{3}$ group(s) (Fig. 1), followed by focused crystallization and structure determination using crystallizable RNA variants with $2^{\prime}-\mathrm{OCH}_{3}$ group(s) substituted for $2^{\prime}-\mathrm{SeCH}_{3} \operatorname{group}(\mathrm{s})$ (Fig. 2). The $2^{\prime}-\mathrm{OCH}_{3}$ group is chemically analogous to the $2^{\prime}-\mathrm{SeCH}_{3}$ group (Fig. 1). However, the incorporation of the $2^{\prime}$ - $\mathrm{OCH}_{3}$-modified nucleoside into RNA is less expensive and easier. As we demonstrate in the current study, RNAs derivatized by either $2^{\prime}-\mathrm{SeCH}_{3}$ or $2^{\prime}-\mathrm{OCH}_{3}$ groups behave similarly in crystallization trials, thus providing an easy, inexpensive, and fast approach to the crystallization and three-dimensional structure determination of various RNA or RNA/protein complexes.

\section{RESULTS AND DISCUSSION}

\section{Structure determination of the HIV-1 DIS/ aminoglycoside complex using selenium-labeled RNA}

The approach has been developed during the structure solution of the 46-nt HIV-1 genomic RNA dimerization initiation site (DIS) bound to aminoglycoside antibiotics. This RNA/drug complex involves a 23-nt RNA homodimer, which promotes viral genome dimerization and is recognized by aminoglycosides (Ennifar et al. 2003, 2007b; Bernacchi et al. 2007; Freisz et al. 2008). In parallel to an extensive but unsuccessful search for heavy atom derivatives, we attempted to determine the structure using 5-halogen-pyrimidine derivatives. Despite multiple trials using 5-bromo- and 5-iodo-RNAs, crystals were obtained only for a 5-iodo derivative. Data sets collected for these crystals at both low-energy (to maximize the anomalous signal) and high-energy (to reduce crystal absorption and radiation damage) wavelengths showed good quality crystallographic statistics (Supplemental Table 1). However, our attempts to determine the structure using multiple isomorphous replacement (MIR), MAD or SAD techniques have failed, most likely because of strong site-specific radiation damage previously reported on 5-halogen pyrimidines (Ennifar et al. 2002). A correction for the radiolysis by a dose-dependent occupancy refinement of iodine atoms, recently implemented in the program SHARP (Schiltz et al. 2004), was not successful. The $2^{\prime}-\mathrm{SeCH}_{3}$ RNA labeling strategy was therefore investigated to determine the structure of the RNA/drug complex.

Three sequences were synthesized with selenium atoms introduced at various positions in the DIS stem: U266, U267, and U270 (Fig. 3). Out of these three sequences, only the $\mathrm{U} 267-\mathrm{SeCH}_{3}$ DIS variant produced diffraction quality crystals. Interestingly, as reported previously for a $2^{\prime}$ $\mathrm{SeCH}_{3}$-labeled DNA duplex (Jiang et al. 2007), these Sederivatized crystals grew significantly faster and larger than crystals with unmodified RNA, leading to an improvement in the diffraction limit (Table 1). Poorly diffracting crystals and spherulites were obtained with the U266- $\mathrm{SeCH}_{3}$ DIS $\mathrm{RNA}$, and no crystals were found for the U270- $\mathrm{SeCH}_{3}$ DIS sequence (Fig. 3). A single U267- $\mathrm{SeCH}_{3}$ crystal was used to collect highly redundant data at the Se-K edge in a threewavelength MAD experiment (Table 1). This data set produced an experimental electron density map of exceptional quality (Fig. 4a), thus emphasizing the high quality of experimental phases obtained from Se-derivatized RNA.

Subsequent examination of the $2^{\prime}-\mathrm{SeCH}_{3}$-modified residues in the structure revealed an intraresidue $\mathrm{C}-\mathrm{H}$ (methyl)-O4(U) hydrogen bond that restricts rotation of

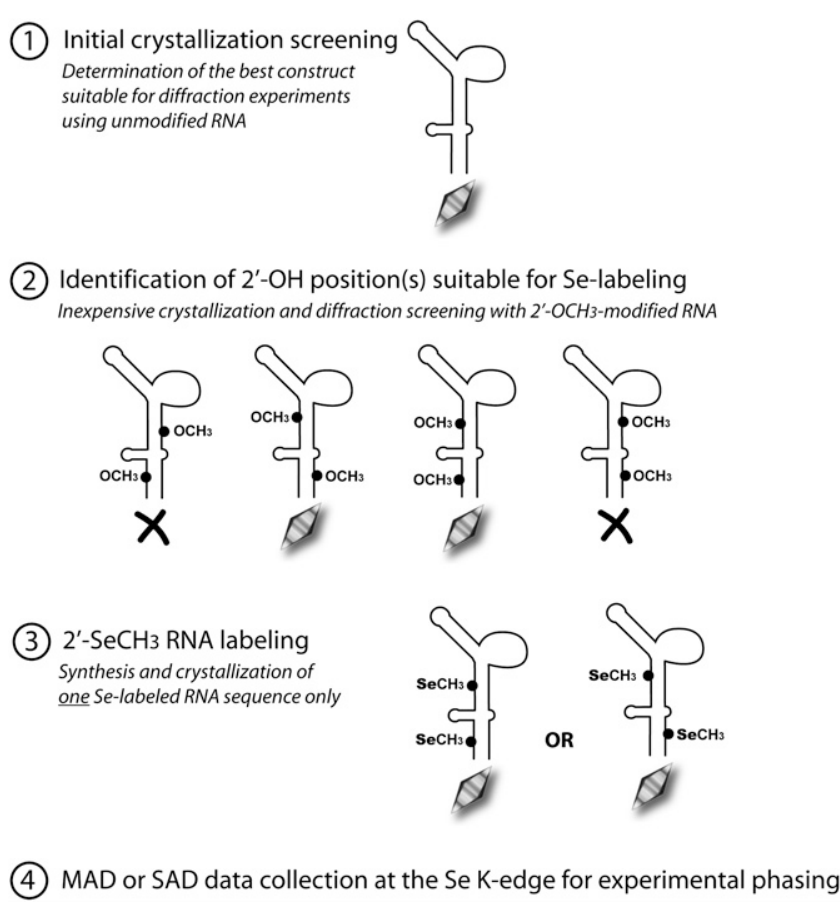

FIGURE 2. Schematic representation of the proposed strategy for selenium derivatization and phasing of RNA crystal structures. 

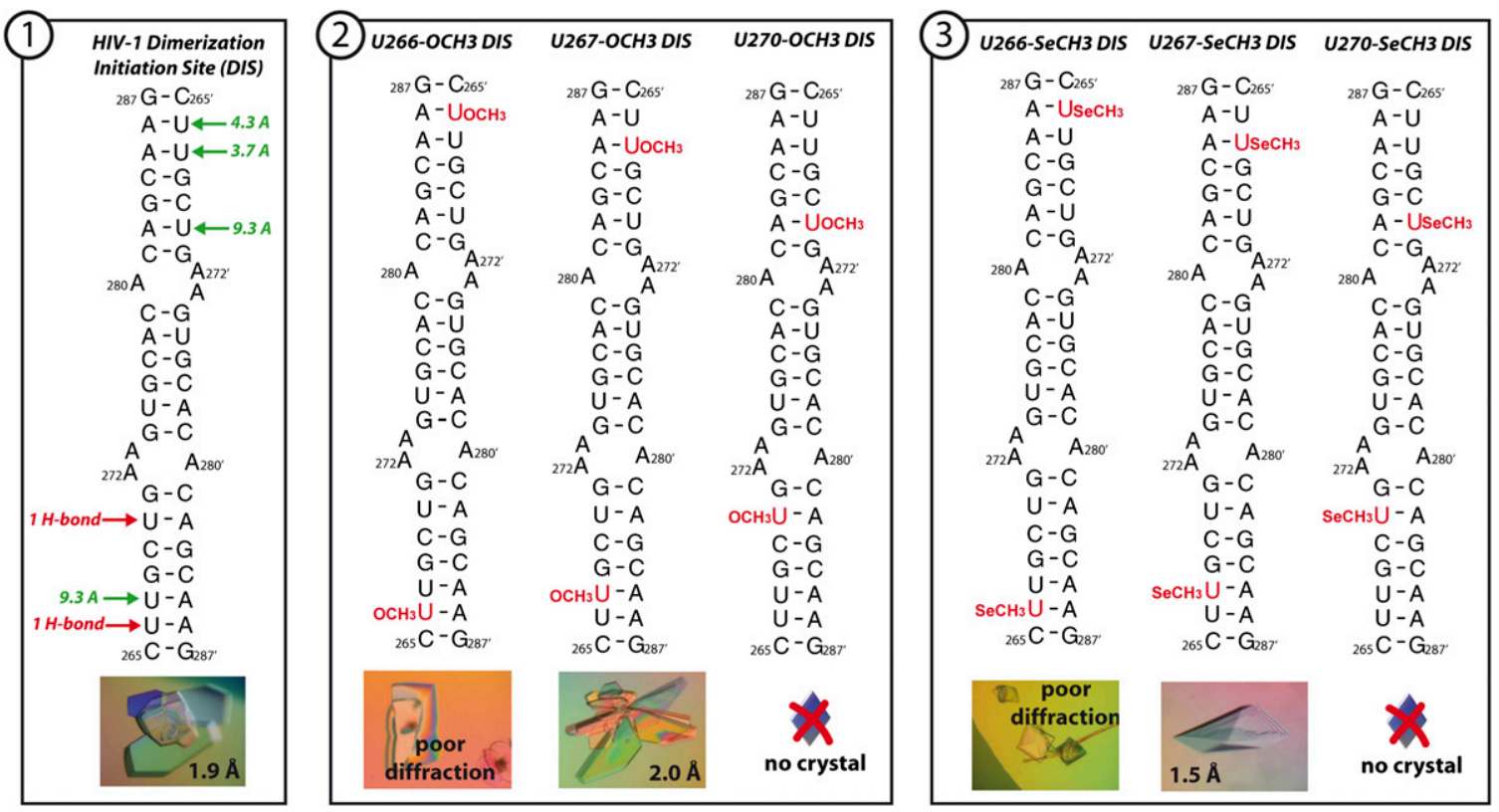

FIGURE 3. Sequences and crystallization results obtained for the HIV-1 genomic RNA dimerization initiation site extended duplex bound to ribostamycin aminoglycoside (Freisz et al. 2008) according to the scheme proposed on Fig. 2. On the unmodified sequence (1)), green and red arrows indicate $2^{\prime}-\mathrm{OH}$ positions available for $2^{\prime}-\mathrm{OCH}_{3} / \mathrm{SeCH}_{3}$ substitution or involved in crystal packing, respectively. The distance to the closest atom is indicated in green for available positions, and the number of hydrogen bonds involved in the packing interaction is shown in red.

TABLE 1. Data collection and refinement statistics for unmodified, $U 267-\mathrm{OCH}_{3}$ and $\mathrm{U} 267-\mathrm{SeCH}_{3}$ DIS RNAs bound to paromomycin or ribostamycin antibiotics (Freisz et al. 2008)

\begin{tabular}{|c|c|c|c|}
\hline & Unmodified DIS/paromomycin & U267-OCH ${ }_{3}$ DIS/ribostamycin & $\begin{array}{l}\text { U267-SeCH } \mathrm{SIS}_{3} \text { DIribostamycin } \\
\text { (Freisz et al. 2008) }\end{array}$ \\
\hline \multicolumn{4}{|l|}{ Data collection } \\
\hline Space group & $\mathrm{C} 2$ & $\mathrm{C} 2$ & $\mathrm{C} 2$ \\
\hline Cell parameters & $\begin{array}{l}a=100.58, b=29.52 \\
c=58.67 ; \beta=121.32^{\circ}\end{array}$ & $\begin{array}{l}a=99.70 ; b=30.49 \\
c=58.00 ; \beta=122.25^{\circ}\end{array}$ & $\begin{array}{l}a=99.54 ; b=30.56 \\
c=57.65 ; \beta=121.37^{\circ}\end{array}$ \\
\hline Beamline & BM30 ESRF & ID23-1 ESRF & ID29 ESRF \\
\hline Wavelength $(\AA)$ & 1.07 & 0.92 & 0.98 \\
\hline Maximum resolution $(\AA)$ & 1.95 & 2.00 & 1.50 \\
\hline High-resolution shell & $2.02-1.95$ & $2.07-2.00$ & $1.55-1.50$ \\
\hline Redundancy & 3.3 & 8.2 & 9.2 \\
\hline Completeness (\%) & $95.7(92.6)$ & $95.6(91.3)$ & $98.6(98.5)$ \\
\hline Rsym (\%) & $3.6(27.1)$ & $5.8(30.9)$ & $5.5(24.3)$ \\
\hline $\mathrm{l} / \sigma$ & $30.9(1.9)$ & $29.0(9.8)$ & $27.9(5.9)$ \\
\hline Anomalous signal & NA & NA & $\mathrm{f}^{\prime \prime}=4.6 \overline{\mathrm{e}}$ \\
\hline \multicolumn{4}{|l|}{ Refinement } \\
\hline Rcryst (\%) & & 26.8 & 22.1 \\
\hline Rfree $(\%)$ & & 27.7 & 22.7 \\
\hline \multicolumn{4}{|l|}{ Number of atoms } \\
\hline Nucleic acids & & 980 & 980 \\
\hline Water & & 44 & 164 \\
\hline Ligand & & 62 & 62 \\
\hline lons & & $4 \mathrm{~K}^{+}, 1 \mathrm{Cl}^{-}$ & 0 \\
\hline PDB ID & & 3DVV & $3 C 3 Z$ \\
\hline
\end{tabular}

Only data collected at the Se K-edge absorption peak are indicated for the $2^{\prime}$-SeCH${ }_{3}$-modified DIS sequence (values for last resolution shell are shown in parentheses); $\mathrm{NA}=$ not available. 
A
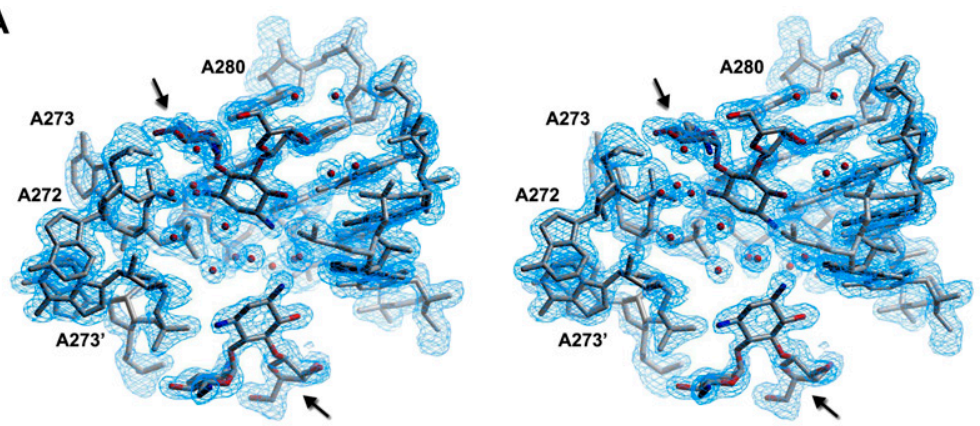

B

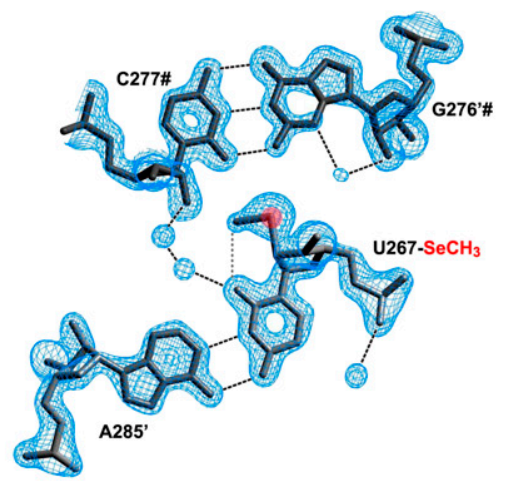

C
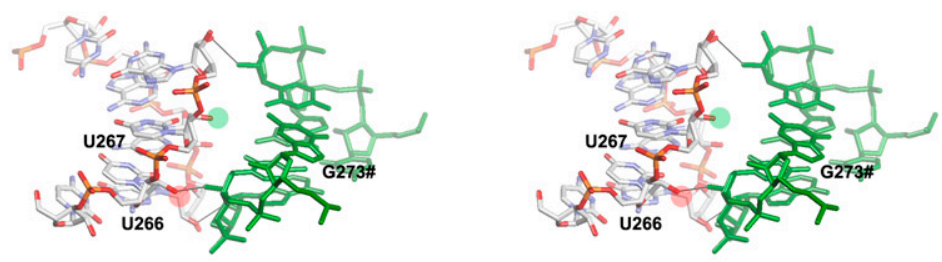

D
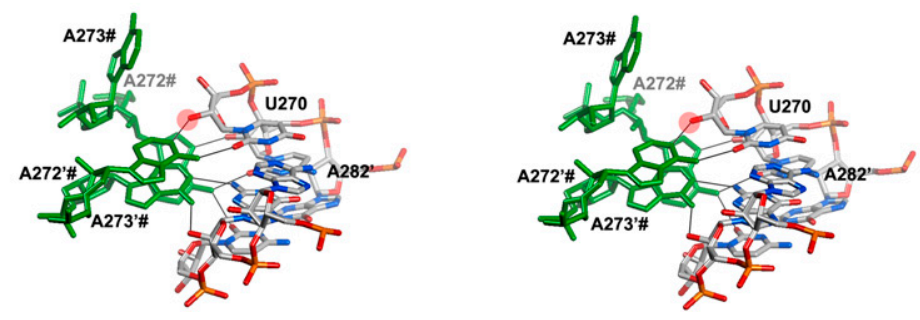

FIGURE 4. HIV-1 DIS RNA/drug complex (Freisz et al. 2008). (A) Stereo view of the experimental MAD electron density map. The map clearly shows the bulge region (A272, A273, A280) of RNA, two ribostamycin aminoglycosides (indicated with black arrows), and surrounding water molecules (red spheres). (B) View of the $\mathrm{U} 267-\mathrm{SeCH}_{3} \mathrm{~A} 285^{\prime}$ base-pair in the HIV DIS structure at $1.5 \AA$ resolution. Se atom is depicted by a pink sphere. $2 \mathrm{Fo}-\mathrm{Fc}$ electron density map is represented around the model. The C277-G276' base-pair from a symmetry-related molecule is also shown. Hydrogen bonds and the intraresidue C-H(methyl)$\mathrm{O}$ bond in the modified uridine are represented with black and gray dotted lines, respectively. $(C, D)$ Stereo views showing crystal packing interactions around U266, U267 $(C)$, and U270 $(D)$ residues. Symmetry-related molecules are shown in green, and nucleotides are indicated with a hash mark (\#). 2'-OH groups of U266 and U270, which do not allow $2^{\prime}-\mathrm{SeCH}_{3}$ modifications, are shown with a pink circle. The $2^{\prime}-\mathrm{OH}$ group of U267, which can accommodate $2^{\prime}-\mathrm{SeCH}_{3}$ modification, is depicted with a green circle. The hydroxyl of U266 interacts with a $2^{\prime}-\mathrm{OH}$ group from a symmetry-related molecule $(C)$, and the hydroxyl of $\mathrm{U} 270$ is involved in an A minor interaction with a bulged-out $\mathrm{A} 272^{\prime} \#(D)$, whereas $2^{\prime}-\mathrm{OH}$ of $\mathrm{U} 267$ is not $\mathrm{H}$-bonded and available for $2^{\prime}-\mathrm{SeCH}_{3}$ modification $(C)$. Residues U266', U267', and U270' from the second molecule in the asymmetric unit are not involved into crystal packing (not shown). the methyl group (Fig. 4b). Analysis of the DIS/ribostamycin crystal structure showed that the $2^{\prime}-\mathrm{OH}$ groups of U266 and U270 in one DIS strand are involved in crystal packing, whereas the 2'-hydroxyl of U267 in both strands does not provide crystal contacts (Fig. 4c,d). We therefore reasoned that the $2^{\prime}-\mathrm{OCH}_{3}$ modification can be regarded as isosteric to the $2^{\prime}-\mathrm{SeCH}_{3}$ one and, thus, could be used to screen $2^{\prime}-\mathrm{OH}$ positions available for the $2^{\prime}-$ $\mathrm{SeCH}_{3}$ modification. To test this hypothesis, a $2^{\prime}-\mathrm{OCH}_{3}$ modification was introduced into U266, U267, and U270 of the DIS RNA (Fig. 3), and the crystallization and diffraction properties of these variants were compared with the crystallization behavior of the corresponding $2^{\prime}-\mathrm{SeCH}_{3}$-modified sequences. As anticipated, the $2^{\prime}-\mathrm{OCH}_{3}-$ modified DIS sequences demonstrated a good correlation with the $2^{\prime}-\mathrm{SeCH}_{3}$ modified RNAs: no crystal was obtained for the U270- $\mathrm{OCH}_{3}$ DIS RNA, spherulites and poorly diffracting crystals were found for the U266$\mathrm{OCH}_{3}$ DIS variant, and well-shaped diffracting crystals were obtained for the U267- $-\mathrm{OCH}_{3}$ DIS RNA (Fig. 3; Table 1).

\section{Validation of the strategy: structure determination of the Escherichia coli sarcin/ricin loop}

We then validated our approach using the 27-nt fragment of E. coli $23 \mathrm{~S}$ rRNA sarcin/ricin loop (SRL) region (Correll et al. 1999). Analysis of the SRL structure (Protein Data Bank [PDB] identification no. 483D) revealed that the $2^{\prime}-\mathrm{OH}$ groups of U2650 and U2656 are not involved in the crystal contacts and, hence, are available for modifications, whereas the 2'-OH of U2653 is hydrogen bonded with a symmetry-related molecule (Fig. 5, (1)). Four SRL sequences were therefore synthesized: an unmodified SRL (used as a control for crystallization and diffraction) and three modified sequences with the introduction of a $2^{\prime}-\mathrm{OCH}_{3}$ group into U2650, U2653, or U2656 (Fig. 5). Crystallization trials revealed that, as expected, only 



FIGURE 5. Sequences used and crystallization results obtained for the E. coli $23 \mathrm{~S}$ rRNA sarcin/ricin loop (Correll et al. 1999) according to the scheme proposed on Fig. 2.

U2650 and U2656 accommodated the $2^{\prime}-\mathrm{OCH}_{3}$ modification and produced crystals, whereas modification of U2653 precluded crystallization (Fig. 5). Following this preliminary $2^{\prime}-\mathrm{OCH}_{3}$ screening of the SRL sequence, $2^{\prime}-\mathrm{SeCH}_{3}$-uridines were introduced at the 2650 and 2656 positions. In agreement with our previous results, both sequences produced crystals in every respect identical to unmodified or $2^{\prime}-\mathrm{OCH}_{3}$ containing SRL sequences, thus confirming the excellent correlation between $2^{\prime}-\mathrm{OCH}_{3}$ and $2^{\prime}-\mathrm{SeCH}_{3}$ modifications. The Se-derivatized SRL crystals were then used for a classical three-wavelength diffraction experiment (Table 2). Both $\mathrm{U} 2650-\mathrm{SeCH}_{3}$ and $\mathrm{U} 2656-\mathrm{SeCH}_{3}$ SRL structures were easily determined by SAD and MAD, which produced similar experimental electron density maps of exceptional quality (Figs. 6, 7), additionally illustrating the efficiency of selenium derivatization. Interestingly, diffraction data collected at atomic resolution for $\mathrm{U} 2650$ - and $\mathrm{U} 2656-\mathrm{OCH}_{3}$ and $-\mathrm{SeCH}_{3}$ SRL confirmed the presence of the C-H(methyl)-O4(U) intraresidue bond that stabilizes the methyl group (Fig. 7).

\section{Site-specific radiation damage studies of $2^{\prime}-\mathrm{SeCH}_{3}$ and comparison with 5-halogen pyrimidines}

To demonstrate the greater resistance to radiation damage of $2^{\prime}-\mathrm{SeCH}_{3}$-labeled over 5-halogen-labeled RNA, a detailed comparison of site-specific radiolysis was performed using DIS or SRL RNA crystals containing $2^{\prime}-\mathrm{SeCH}_{3}$ modifications, and 5-bromo- or 5-iodo-uridines. Using heavy atom occupancies derived from the anomalous signal that was calculated from small data subsets (Olieric et al. 2007), we found that radiolysis had little effect on the C-Se bond. In contrast, 5-iodo- and 5-bromo-uridines are significantly affected by site-specific radiation damage during data collection (Fig. 8). The resistance toward radiolysis accounts for the excellent quality of $\mathrm{SAD} /$ MAD experimental maps obtained from 2 ' $-\mathrm{SeCH}_{3}$ RNA derivatives, thus reinforcing its interest for nucleic acids phasing.

\section{Conclusion}

Our results demonstrate excellent correlation in the crystallization of $2^{\prime}-\mathrm{OCH}_{3}-$ and $2^{\prime}-\mathrm{SeCH}_{3}$-modified RNAs and suggest the use of $2^{\prime}-\mathrm{OCH}_{3}$-modified RNA sequences for a preliminary search of $2^{\prime}-\mathrm{OH}$ groups available for selenium labeling (Fig. 2). The introduction of $2^{\prime}-\mathrm{OCH}_{3}$ groups can be routinely achieved by chemical synthesis. The low costs of $2^{\prime}-\mathrm{OCH}_{3}$ ribonucleotide building blocks make this approach less expensive than the synthesis of multiple variants of $2^{\prime}$ $\mathrm{SeCH}_{3}$-modified RNA. The greatest advantage, however, is the efficiency of screening with $2^{\prime}-\mathrm{OCH}_{3}$ nucleosides: the extensive time required for multistep syntheses of commercially unavailable Se-modified adenosine, cytosine, and guanosine nucleoside phosphoramidites is compensated by high hit-rate structure determination when Se-labels are only positioned at the most promising sites that have been identified via $2^{\prime}$ $\mathrm{OCH}_{3}$ nucleosides. This strategy can obviously be extended to structure determination of RNA (or DNA)/protein complexes when the classical approach with selenomethionine-modified proteins failed. Based upon what is commonly considered for the structure determination of proteins (about one selenomethionine per $20 \mathrm{kDa}$ ), one $\mathrm{SeCH}_{3}$-modified position (preferably in a canonical helical region) per $\sim 50 \mathrm{nt}$ is probably a safe rule. We also anticipate that $2^{\prime}-\mathrm{OCH}_{3}$-modified RNA can be directly used for the initial screening of crystallization conditions, thereby eliminating the search for crystallization conditions using unmodified RNA. Finally, our data show that, unlike 5-halogen pyrimidines, 2' $-\mathrm{SeCH}_{3}$-modified nucleosides are strongly resistant to site-specific radiation damage and are therefore more suitable for SAD or MAD experiments, especially using small crystals and third generation synchrotrons. 


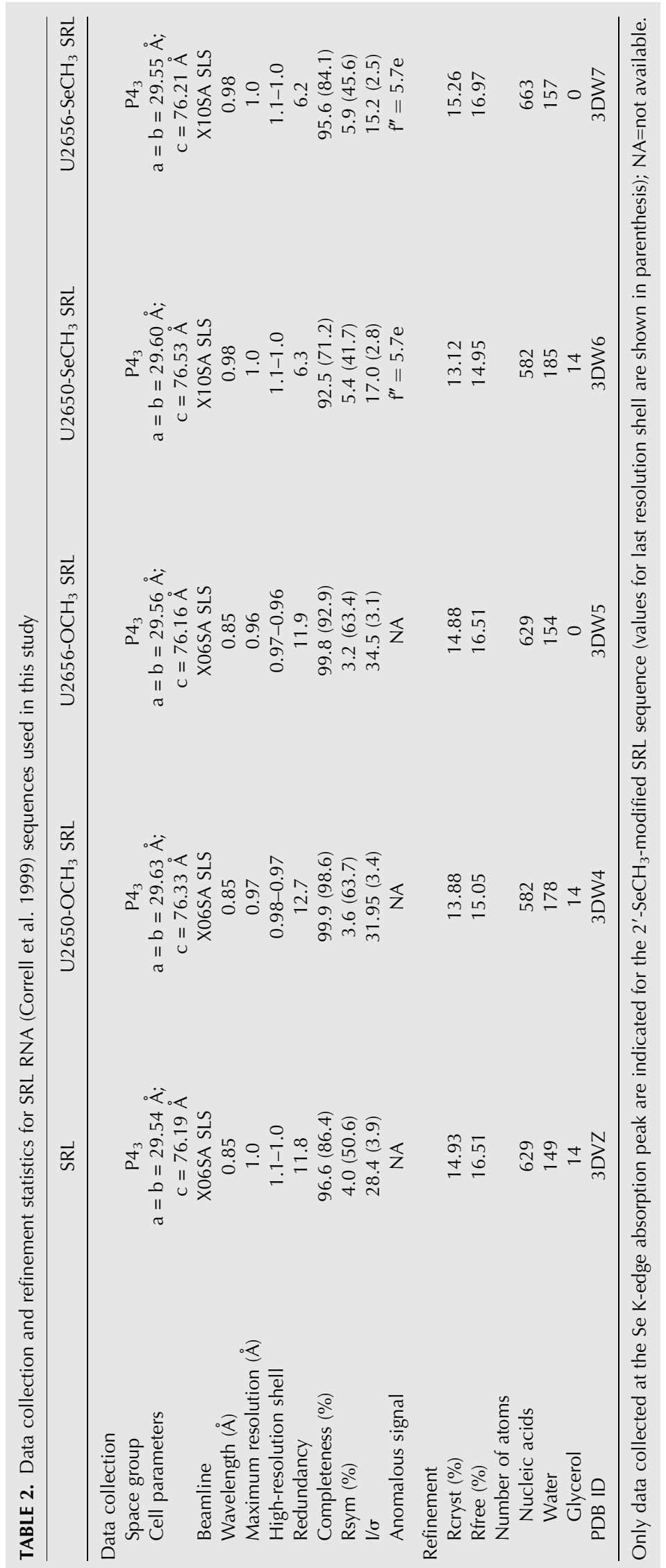


A

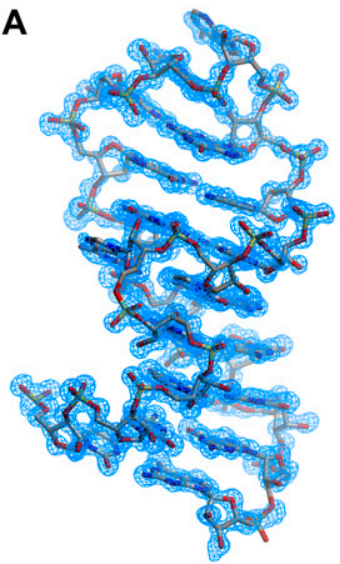

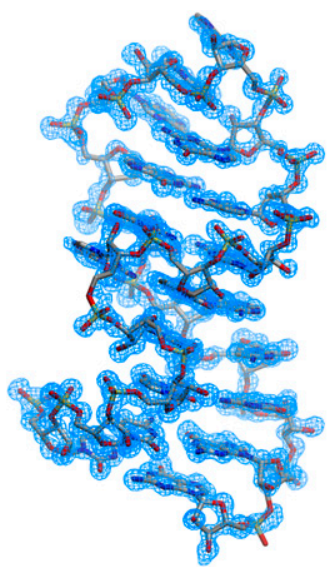

B



FIGURE 6. Experimental MAD electron density map (contoured at $1.5 \sigma$ level) obtained with the U2656-SeCH $\mathrm{S}_{3} \mathrm{SRL}_{\mathrm{RNA}}$. (A) Stereo view showing residues 2651-2669. (B) Detailed view of the A2657-G2664 mismatch. Electron density maps of similar quality were obtained by SAD phasing with $\mathrm{U} 2656-\mathrm{SeCH}_{3} \mathrm{RNA}$, and by MAD/SAD phasing with the U2650- $\mathrm{SeCH}_{3}$ SRL sequence.

\section{MATERIAL AND METHODS}

\section{Chemical synthesis of RNA}

Unmodified 23-nt DIS, 5-bromo- and 5-iodo-uridine DIS, and 2'$\mathrm{OCH}_{3}$-modified DIS sequences were purchased from Dharmacon. All RNAs containing 2'-methylseleno uridines were synthesized according to previously published procedures (for details, see Hobartner and Micura 2004; Micura et al. 2007). To guarantee a broad dissemination of the approach presented here, we exemplify the $2^{\prime}-\mathrm{OCH}_{3} / 2^{\prime}-\mathrm{SeCH}_{3}$ strategy for uridine since the corresponding $2^{\prime}-\mathrm{SeCH}_{3}$-uridine phosphoramidite is commercially available (http://www.glenresearch.com). The syntheses of $2^{\prime}-\mathrm{SeCH}_{3}$ cytidine, $2^{\prime}-\mathrm{SeCH}_{3}$ adenine, and $2^{\prime}-\mathrm{SeCH}_{3}$ guanosine phosphoramidites have been described (Hobartner et al. 2005; Moroder et al. 2006; Puffer et al. 2008), however, these building blocks have not yet been commercialized. The approach presented here works in similar manner for adenine, cytidine, and guanosine (data not shown).

\section{Crystallization of RNA samples, data processing, and structure refinement}

The HIV-1 DIS duplexes bound to ribostamycin or paromomycin aminoglycosides were crystallized as described previously (Freisz et al. 2008). Crystals were grown for $7-10 \mathrm{~d}$ at $37^{\circ} \mathrm{C}$ with unmodified and with 5-iodo-U266 sequences, and for 1-2 d at $37^{\circ} \mathrm{C}$ with $\mathrm{U} 267-\mathrm{SeCH}_{3}$ DIS RNA. No DTT was added to crystallization conditions to prevent possible oxidization of the $2^{\prime}-\mathrm{SeCH}_{3}$ groups to $2^{\prime}$-methylselenoxide (Moroder et al. 2006). No crystals were lines, respectively. obtained with 5-iodo-U267, 5-bromo-U266, or 5-bromo-U267 modified RNA. Crystals were frozen in liquid ethane prior data collection. Data were processed with the HKL Package (Otwinowski and Minor 1996) and $D^{\star}$ TREK (Pflugrath 1999). The asymmetric unit (A.U.) contains two DIS molecules and two aminoglycosides. Two heavy atoms in the A.U. were located with SHELX (Sheldrick 2008), and the structure was solved using SHARP (de la Fortelle and Bricogne 1997). For radiation damage studies, 5-iodo- and 5-bromo-U267 DIS loop-loop complex bound to lividomycin

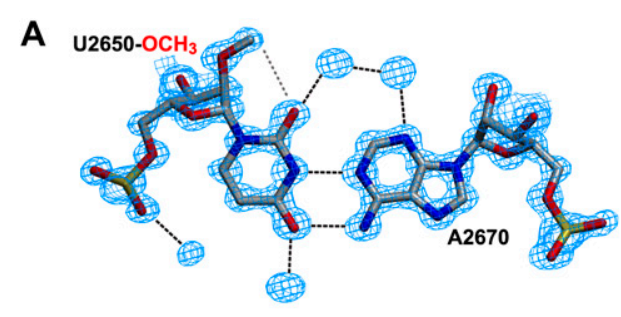

C

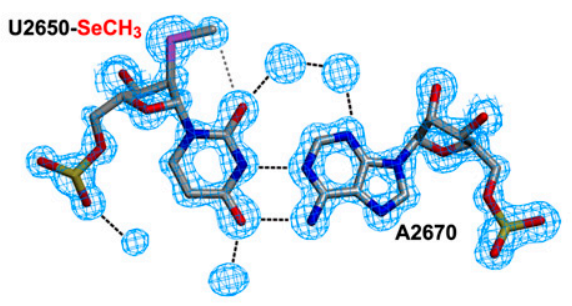

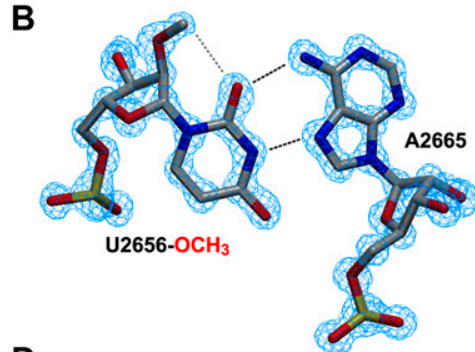

D

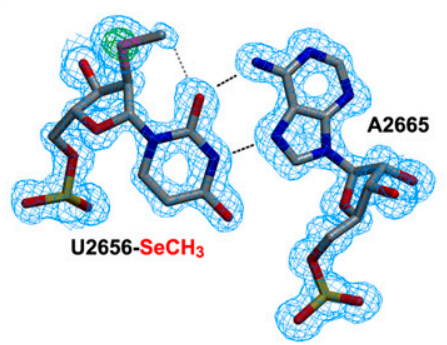

FIGURE 7. Detailed views of the labeled U2650 A2670 $(A, C)$ and of the labeled U2656.A2665 reverse wobble $(B, D)$ base-pairs in SRL structures. $(A, B)$ The 2Fo-Fc electron density map at $0.97 \AA$ and $0.96 \AA$ resolution are represented around the refined model. $(C)$ The experimental SAD electron density map at $1.1 \AA$ resolution is shown around the $\mathrm{U} 2650-\mathrm{SeCH}_{3} \mathrm{~A} 2670$. (D) The experimental MAD electron density map at $1.0 \AA$ resolution, as well as the anomalous map contoured at $40 \sigma$ level (in green), is shown for the U2656-SeCH${ }_{3}$ SRL structure. Spheres of electron density around RNA correspond to water molecules. Hydrogen bonds and the intraresidue $\mathrm{C}-\mathrm{H}$ (methyl)-O bond in modified uridines are represented with black and gray dotted 


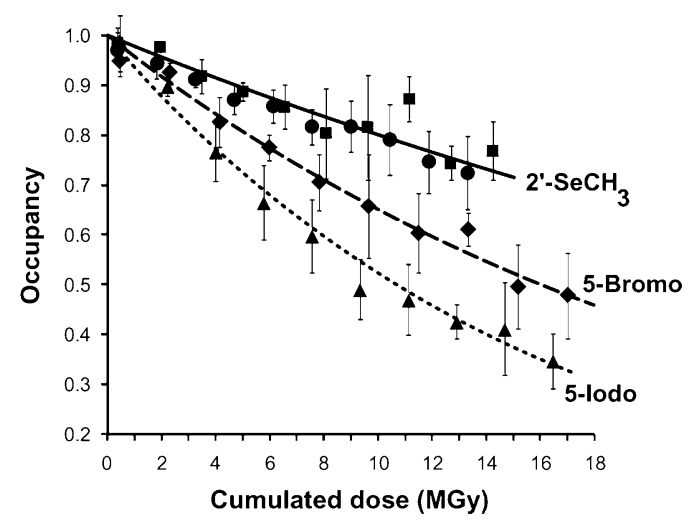

FIGURE 8. Site-specific radiation damage studies of modified RNA. Comparison of occupancies derived from anomalous difference maps for data collected on U267-Iodo DIS (triangle, dotted line), U267Bromo DIS (diamonds, dashed line), U267- $\mathrm{SeCH}_{3}$ DIS (squares), and U2656- $\mathrm{SeCH}_{3}$ SRL (spheres) RNA crystals. The cumulative dose limit of 15 - 18 MGy was chosen as it corresponds to the upper limit of doses typically absorbed by a crystal during MAD or SAD data collection.

aminoglycoside were crystallized as described earlier (Ennifar et al. 2006) and frozen in liquid ethane.

The 27-nt SRL hairpin was crystallized according to the method described by Correll et al. (1999). This sequence was chosen as a test case because crystallization conditions easily produce welldiffracting crystals. Crystals were grown for $1-3 \mathrm{~d}$ at $20^{\circ} \mathrm{C}$ for unmodified, $2^{\prime}-\mathrm{OCH}_{3}$-modified, and $2^{\prime}$ - $\mathrm{SeCH}_{3}$-modified sequences. About $80 \%$ of drops produced crystals (18 drops were prepared for each SRL sequence). Glycerol was used instead of xylitol for cryoprotection, and crystals were frozen in liquid ethane for data collection. Data were processed with the XDS Package (Kabsch 1993) and D*TREK. The A.U. contains one SRL molecule. Heavy atom searches and structure determination were performed with SHELX.

Structures were refined with CNS (Brunger et al. 1998) and PHENIX (Adams et al. 2002). Because of high B factors, the methyl group was not visible on both strands in the $\mathrm{U} 267-\mathrm{OCH}_{3}$ DIS structure at $2.0 \AA$ resolution and on one strand on the U267$\mathrm{SeCH}_{3}$ DIS structure at $1.5 \AA$ resolution. Coordinates have been deposited to the PDB.

\section{Site-specific radiation damage analysis}

All radiation damage experiments were carried out at the X06SA macromolecular crystallography beamline of the Swiss Light Source (SLS) at Paul Scherrer Institut, Villigen, Switzerland. Data were collected at $90 \mathrm{~K}$ on a Pilatus $6 \mathrm{M}$ detector (Dectris AG) on five U2656- $\mathrm{SeCH}_{3}$ SRL crystals, two U267- $\mathrm{SeCH}_{3}$ DIS duplex/ Ribostamycin crystals (Freisz et al. 2008), four U267-Bromo DIS kissing-complex/Lividomycin crystals (Ennifar et al. 2006), and three U267-Iodo DIS kissing-complex/Lividomycin crystals (Ennifar et al. 2007a). Data for seleno and iodo derivatives were collected at $12.6647 \mathrm{keV}$ and at $13.4895 \mathrm{keV}$ for bromo derivatives. For all crystals, $3600^{\circ}$ ( 7200 images) were collected in a row with a rotation increment of $0.5^{\circ}$ per image and an exposure time of $0.2 \mathrm{sec}$ per image. Such data collection took only $24 \mathrm{~min}$ using the Pilatus $6 \mathrm{M}$ detector. The $\mathrm{X}$-ray beam was defocused in the vertical direction $(150 \times 80 \mu \mathrm{m})$ to obtain homogenous X-ray irradiation of the crystal during data collection (Schulze-Briese et al. 2005). Beam transmission was adapted to reach a dose of $\sim 15 \mathrm{MGy}$ at the end of each data collection. The incident photon flux was monitored by using a PIN diode, and the beam position was monitored using a CVD diamond quadrant beam-position monitor. The doses were calculated with the program Raddose (Murray et al. 2005), taking into account the fluorescence correction. The $3600^{\circ}$ were split into 20 sets $\left(180^{\circ}\right.$ each), which were processed independently with XDS. Occupancies of the anomalous scatterers were derived from the anomalous difference maps calculated with the anomalous differences for each of the 20 data sets according to the method performed by Olieric et al. (2007).

Of course, we cannot exclude a possible influence on radiation damage of RNA sequence and crystallization conditions. However, in the present study, a great care was taken to compare heavy atoms $(\mathrm{Br}, \mathrm{I}$, or $\mathrm{Se})$ with very similar parameters. For instance bromo-, iodo-, and seleno-labeled DIS RNA structures were compared only for the same RNA sequence, and only when crystallized in highly similar conditions, thus ruling out any influence of buffer, salts or RNA construct. In addition, results obtained for the Se-labeled DIS RNA were very comparable to those with Se-labeled SRL RNA crystallized in different conditions, and we are therefore confident in the presented results. In addition, because a potential influence of crystal environment on the site-specific radiation damage was suspected in some studies (Ramagopal et al. 2005), only atoms with low accessible surface area (ranging from 1 to $13 \AA^{2}$ with a $1.4 \AA$ probe radius) were considered in the present study. However, since other studies (Burmeister 2000; Ravelli and McSweeney 2000; Fioravanti et al. 2007) are in contradiction with a significant effect of the solvent accessibility, we are quite confident that our results can be generalized for most cases.

\section{SUPPLEMENTAL MATERIAL}

Supplemental material can be found at http://www.rnajournal.org.

\section{ACKNOWLEDGMENTS}

We thank Marc Schiltz for his support during RIP-phasing trials of the DIS structure. This work was supported by the Agence Nationale de Recherche sur le SIDA (ANRS), the French Research Agency (ANR; project PCV07-187047), and the Austrian Science Fund (FWF; project P17864).

Received December 5, 2008; accepted January 9, 2009.

\section{REFERENCES}

Adams, P.D., Grosse-Kunstleve, R.W., Hung, L.W., Ioerger, T.R., McCoy, A.J., Moriarty, N.W., Read, R.J., Sacchettini, J.C., Sauter, N.K., and Terwilliger, T.C. 2002. PHENIX: building new software for automated crystallographic structure determination. Acta Crystallogr. D Biol. Crystallogr. 58: 1948-1954.

Bernacchi, S., Freisz, S., Maechling, C., Spiess, B., Marquet, R., Dumas, P., and Ennifar, E. 2007. Aminoglycoside binding to the HIV-1 RNA dimerization initiation site: Thermodynamics and 
effect on the kissing-loop to duplex conversion. Nucleic Acids Res. 35: 7128-7139.

Brunger, A.T., Adams, P.D., Clore, G.M., DeLano, W.L., Gros, P., Grosse-Kunstleve, R.W., Jiang, J.S., Kuszewski, J., Nilges, M., Pannu, N.S., et al. 1998. Crystallography \& NMR system: A new software suite for macromolecular structure determination. Acta Crystallogr. D Biol. Crystallogr. 54: 905-921.

Burmeister, W.P. 2000. Structural changes in a cryo-cooled protein crystal owing to radiation damage. Acta Crystallogr. D Biol. Crystallogr. 56: 328-341.

Carrasco, N., Buzin, Y., Tyson, E., Halpert, E., and Huang, Z. 2004. Selenium derivatization and crystallization of DNA and RNA oligonucleotides for X-ray crystallography using multiple anomalous dispersion. Nucleic Acids Res. 32: 1638-1646.

Correll, C.C., Wool, I.G., and Munishkin, A. 1999. The two faces of the Escherichia coli $23 \mathrm{~S}$ rRNA sarcin/ricin domain: The structure at 1.11 A resolution. J. Mol. Biol. 292: 275-287.

de la Fortelle, E. and Bricogne, G. 1997. Maximum-likelihood heavyatom parameter refinement for multiple isomorphous replacement and multiwavelength anomalous diffraction methods. In Macromolecular crystallography (eds. C.W. Carter Jr. and R.M. Sweet), pp. 472-494. Academic Press, New York.

Du, Q., Carrasco, N., Teplova, M., Wilds, C.J., Egli, M., and Huang, Z. 2002. Internal derivatization of oligonucleotides with selenium for X-ray crystallography using MAD. J. Am. Chem. Soc. 124: 24-25.

Ennifar, E., Carpentier, P., Ferrer, J.L., Walter, P., and Dumas, P. 2002. X-ray-induced debromination of nucleic acids at the $\mathrm{Br} \mathrm{K}$ absorption edge and implications for MAD phasing. Acta Crystallogr. D Biol. Crystallogr. 58: 1262-1268.

Ennifar, E., Paillart, J.C., Marquet, R., Ehresmann, B., Ehresmann, C., Dumas, P., and Walter, P. 2003. HIV-1 RNA dimerization initiation site is structurally similar to the ribosomal A site and binds aminoglycoside antibiotics. J. Biol. Chem. 278: 2723-2730.

Ennifar, E., Paillart, J.C., Bodlenner, A., Walter, P., Weibel, J.M., Aubertin, A.M., Pale, P., Dumas, P., and Marquet, R. 2006. Targeting the dimerization initiation site of HIV-1 RNA with aminoglycosides: From crystal to cell. Nucleic Acids Res. 34: 2328-2339.

Ennifar, E., Bernacchi, S., Wolff, P., and Dumas, P. 2007a. Influence of C-5 halogenation of uridines on hairpin versus duplex RNA folding. RNA 13: 1445-1452.

Ennifar, E., Paillart, J.C., Bernacchi, S., Walter, P., Pale, P., Decout, J.L., Marquet, R., and Dumas, P. 2007b. A structurebased approach for targeting the HIV-1 genomic RNA dimerization initiation site. Biochimie 89: 1195-1203.

Fioravanti, E., Vellieux, F.M., Amara, P., Madern, D., and Weik, M. 2007. Specific radiation damage to acidic residues and its relation to their chemical and structural environment. J. Synchrotron Radiat. 14: 84-91.

Freisz, S., Lang, K., Micura, R., Dumas, P., and Ennifar, E. 2008. Binding of aminoglycoside antibiotics to the duplex form of the HIV-1 genomic RNA dimerization initiation site. Angew. Chem. Int. Ed. Engl. 47: 4110-4113.

Hobartner, C. and Micura, R. 2004. Chemical synthesis of seleniummodified oligoribonucleotides and their enzymatic ligation leading to an U6 SnRNA stem-loop segment. J. Am. Chem. Soc. 126: 1141-1149.

Hobartner, C., Rieder, R., Kreutz, C., Puffer, B., Lang, K., Polonskaia, A., Serganov, A., and Micura, R. 2005. Syntheses of RNAs with up to 100 nucleotides containing site-specific 2 '-methylseleno labels for use in X-ray crystallography. J. Am. Chem. Soc. 127: 12035-12045.

Jiang, J., Sheng, J., Carrasco, N., and Huang, Z. 2007. Selenium derivatization of nucleic acids for crystallography. Nucleic Acids Res. 35: 477-485.
Kabsch, W. 1993. Automatic processing of rotation diffraction data from crystals of initially unknown symmetry and cell constants. J. Appl. Crystallogr. 26: 795-800.

Micura, R., Hobartner, C., Rieder, R., Kreutz, C., Puffer, B., Lang, K., and Moroder, H. 2007. Preparation of 2'-deoxy-2'-methylselenomodified phosphoramidites and RNA. In Current protocols in nucleic acid chemistry (eds. S.L. Beaucage et al.), Chap. 1, pp. 1.15.1-1.15.34. Wiley, New York.

Moroder, H., Kreutz, C., Lang, K., Serganov, A., and Micura, R. 2006. Synthesis, oxidation behavior, crystallization, and structure of 2' methylseleno guanosine containing RNAs. J. Am. Chem. Soc. 128: 9909-9918.

Murray, J.W., Rudino-Pinera, E., Owen, R.L., Grininger, M., Ravelli, R.B., and Garman, E.F. 2005. Parameters affecting the $\mathrm{X}$-ray dose absorbed by macromolecular crystals. J. Synchrotron Radiat. 12: 268-275.

Olieric, V., Ennifar, E., Meents, A., Fleurant, M., Besnard, C., Pattison, P., Schiltz, M., Schulze-Briese, C., and Dumas, P. 2007. Using X-ray absorption spectra to monitor specific radiation damage to anomalously scattering atoms in macromolecular crystallography. Acta Crystallogr. D Biol. Crystallogr. 63: 759-768.

Otwinowski, Z. and Minor, W. 1996. Processing of X-ray diffraction data collected in oscillation mode. In Methods in enzymology (eds. C.W. Carter Jr. and R.M. Sweet), pp. 307-326. Academic Press, New York.

Pallan, P.S. and Egli, M. 2007. Selenium modification of nucleic acids: Preparation of oligonucleotides with incorporated 2'-SeMeuridine for crystallographic phasing of nucleic acid structures. Nat. Protocols 2: 647-651.

Pflugrath, J.W. 1999. The finer things in X-ray diffraction data collection. Acta Crystallogr. D Biol. Crystallogr. 55: 1718-1725.

Puffer, B., Moroder, H., Aigner, M., and Micura, R. 2008. 2'Methylseleno-modified oligoribonucleotides for X-ray crystallography synthesized by the ACE RNA solid-phase approach. Nucleic Acids Res. 36: 970-983.

Ramagopal, U.A., Dauter, Z., Thirumuruhan, R., Fedorov, E., and Almo, S.C. 2005. Radiation-induced site-specific damage of mercury derivatives: Phasing and implications. Acta Crystallogr. D Biol. Crystallogr. 61: 1289-1298.

Ravelli, R.B. and McSweeney, S.M. 2000. The "fingerprint" that X-rays can leave on structures. Structure 8: 315-328.

Schiltz, M., Dumas, P., Ennifar, E., Flensburg, C., Paciorek, W., Vonrhein, C., and Bricogne, G. 2004. Phasing in the presence of severe site-specific radiation damage through dose-dependent modelling of heavy atoms. Acta Crystallogr. D Biol. Crystallogr. 60: 1024-1031.

Schulze-Briese, C., Wagner, A., Tomizaki, T., and Oetiker, M. 2005. Beam-size effects in radiation damage in insulin and thaumatin crystals. J. Synchrotron Radiat. 12: 261-267.

Serganov, A., Keiper, S., Malinina, L., Tereshko, V., Skripkin, E., Hobartner, C., Polonskaia, A., Phan, A.T., Wombacher, R., Micura, R., et al. 2005. Structural basis for Diels-Alder ribozyme-catalyzed carbon-carbon bond formation. Nat. Struct. Mol. Biol. 12: 218-224.

Sheldrick, G.M. 2008. A short history of SHELX. Acta Crystallogr. A 64: 112-122.

Teplova, M., Wilds, C.J., Wawrzak, Z., Tereshko, V., Du, Q., Carrasco, N., Huang, Z., and Egli, M. 2002. Covalent incorporation of selenium into oligonucleotides for X-ray crystal structure determination via MAD: Proof of principle. Multiwavelength anomalous dispersion. Biochimie 84: 849-858. 

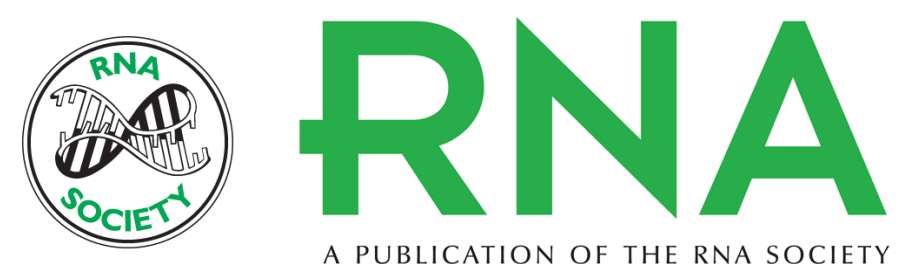

A PUBLICATION OF THE RNA SOCIETY

\section{A fast selenium derivatization strategy for crystallization and phasing of RNA structures}

Vincent Olieric, Ulrike Rieder, Kathrin Lang, et al.

RNA 2009 15: 707-715 originally published online February 18, 2009

Access the most recent version at doi:10.1261/rna.1499309

\section{Supplemental http://rnajournal.cshlp.org/content/suppl/2009/02/23/rna.1499309.DC1 \\ Material}

References This article cites 31 articles, 2 of which can be accessed free at: http://rnajournal.cshlp.org/content/15/4/707.full.html\#ref-list-1

\section{License}

Email Alerting Receive free email alerts when new articles cite this article - sign up in the box at the Service top right corner of the article or click here. 